\title{
Creaciones abstractas en la escultura pública extremeña
}

\author{
Moisés Bazán de Huerta \\ Universidad de Extremadura
}

\section{RESUMEN}

La escultura pública en Extremadura se expresa habitualmente con fórmulas tradicionales y figurativas. Entre sus temas predominan los retratos y los tributos a personajes históricos. Hay también un fuerte componente alegórico, orientado a ensalzar principios democráticos y de convivencia. Y destacan por último aquellas manifestaciones que tienden a recuperar señas de identidad, a través de la monumentalización del mundo laboral y rural.

La escultura abstracta es más reciente y tiene menor presencia en este panorama, pero adquiere una dimensión relevante. Primero porque introduce lenguajes plásticos más innovadores. Y también porque ha permitido la incorporación de nombres importantes de la escultura española, en diálogo con artistas del ámbito local. Interesan además la relación entre la abstracción y su poder evocativo y su difícil recepción por la ciudadanía. El artículo reflexiona sobre estos temas a partir de una selección de ejemplos significativos.

\section{PALABRAS CLAVE:}

Escultura, Arte público, Abstracción, Arte abstracto, Extremadura.

\section{ABSTRACT}

Public sculpture is usually expressed in Extremadura (Spain) with figurative and traditional formulas. Among its themes, portraits and tributes to historical figures are protruded. There is also a strong allegorical component, aimed at extolling democratic principles of coexistence. And, finally, those events that tend to recover identity are highlighted, through the monumentalization of the working world and rural themes.

The abstract sculpture is more recent and has less presence in this scene, but it acquires a relevant dimension. First, it introduces innovative visual languages. And also because it has allowed the incorporation of important names in Spanish sculpture, in dialogue with local artists. Also is interesting the relationship between abstraction, and its evocative power, and its difficult reception by the public. The article reflects about these themes from a selection of significant examples.

\section{KEY WORDS:}

Sculpture, Public Art, Abstraction, Abstract Art, Extremadura.

1 Este texto ha contado con Ayuda del S.E.C.T.I. (Sistema Extremeño de Ciencia y Tecnología e Innovación) al Grupo de Investigación de la Junta de Extremadura "Arte y Patrimonio Moderno y Contemporáneo (HUM 012)". 
Tradicionalmente la escultura pública se ha manifestado a través del monumento conmemorativo, vehículo fundamental para la configuración de una memoria colectiva, por cuanto fija en el recuerdo y para el futuro personajes, legados, ideas, profesiones o situaciones apreciadas por la sociedad en cada momento. Su presencia visible es una forma de perennizar dichos valores, por lo que se convierte en un inestimable testimonio cultural. Extremadura, obviamente, no es ajena a ello, y entre los temas predominantes figuran los retratos y los tributos a personajes históricos, como los vinculados a la conquista americana. Es también habitual la aparición de tipos populares, hondamente caracterizados; así como la representación de oficios, ligados generalmente al ámbito rural, hasta constituir una suerte de neocostumbrismo escultórico. En esta línea, se detecta también una suplantación de la estatuaria por otros elementos de origen industrial que, una vez perdida su función, se han ido colocando en rotondas y plazas. Aparece por último un fuerte componente alegórico, orientado a ensalzar principios democráticos y de convivencia ${ }^{2}$.

Es éste un marco que se presta poco a la renovación, y por ello las propuestas con una cierta modernidad son minoritarias ${ }^{3}$. Aún menos frecuentes son las creaciones abstractas, que se revelan como un fenómeno muy tardío. La escultura pública permaneció ajena al intenso debate sobre la abstracción que se produce en la España de los años cincuenta y sesenta, y que se circunscribe prioritariamente a la pintura o la escultura de galería ${ }^{4}$. Su aplicación al ámbito mo-

2 Para tener una visión, al menos parcial, de este panorama, ver LOZANO BARTOLOZZI, María del Mar, Escultura pública y monumentos conmemorativos en Cáceres, Cáceres, Universidad de Extremadura, 1987; SUÁREZ CABALLER0, Federico y PÉREZ AGUILAR, Beatriz, Extremadura y sus simbolos parlantes. Guía para curiosos y desavisados. I y II, Badajoz, Universitas Editorial, 1999. El autor de este artículo tiene en trámite de publicación un amplio trabajo sobre "Referencias romanas en la escultura pública emeritense”.

3 Para revisar distintos aspectos del tema, ver SOBRINO MANZANARES, María Luisa, Escultura contemporánea en el espacio urbano, Fundación Caixa Galicia-Electa, 1999; MADERUELO, Javier y Otros, Poéticas del lugar. Arte público en España, Lanzarote, Fundación César Manrique, 2001; FINE, Marc, Espacios urbanos, México-Barcelona, Atrium, 2002; SENIE, Harriet F., Contemporary Public Sculptures, New York, Oxford University Press, 1992.

4 El comentario no implica restar fuerza a la potente generación de escultores abstractos (al menos en parte de su producción) que en un amplio período triunfan dentro y fuera de nuestras fronteras (con los precedentes en numental en una región periférica como Extremadura simplemente no se planteó, pero lo llamativo es que, salvo excepciones, la situación se prolongara durante casi otras dos décadas. Cabe explicarlo en el sustento por inercia de unos modos tradicionales y en la escasa apertura de criterios de la clase política (en gran medida responsable de estas iniciativas), por su propia formación y por entender que la figuración es más rentable al conectar mejor con la ciudadanía. Sólo a fines del siglo XX se fueron superando estos recelos $y$, aunque parcialmente, se asume que la abstracción puede ser también un vehículo comunicativo válido. Su papel en Extremadura es importante porque introduce lenguajes plásticos innovadores y porque ha permitido la incorporación de nombres relevantes de la escultura española, en diálogo con artistas del ámbito local.

Uno de los fenómenos más interesantes de esta recuperación de la escultura pública es su uso como elemento regenerador de espacios urbanos, campo de plena actualidad en muchas zonas y que está siendo objeto de estudios sistemáticos ${ }^{5}$, aunque en Extremadura su impacto sea limitado ${ }^{6}$. La ubicación de las piezas escogidas para este estudio no refleja pautas comunes, ya que ocupan espacios muy diversos: carreteras, ro-

el metal de Gargallo, González y Picasso, cabe citar a Ferrant, Alberto, Oteiza, Chillida, Serrano, Palazuelo, Chirino, Gabino, Sempere, Duarte, Ibarrola, Alfaro, Feliciano, Villèlia...). La bibliografía sobre el citado debate teórico es copiosa, pero como referencia reciente puede verse DÍAZ SÁNCHEZ, Julián, La idea de arte abstracto en la España de Franco, Madrid, Cátedra, 2013.

5 Ver, entre otros, REMESAR, Antoni (Ed.), Urban Regeneration. A Challenge for Public Art, Barcelona, Universitat de Barcelona, 1997; FERNÁNDEZ QUESADA, Blanca y LORENTE, Jesús Pedro (Eds.), Arte en el espacio público: barrios artísticos y revitalización urbana, Zaragoza, Prensas Universitarias de Zaragoza, 2009; ÁLVAREZ MARTÍNEZ, María Soledad, "El arte como recurso: intervenciones escultóricas y propuestas artísticas en la regeneración de las villas costeras asturianas" en Frentes maritimos. Memoria del litoral. Actuaciones propuestas $y$ espacios de vida. Ábaco, Revista de cultura y Ciencias Sociales. Monográfico, $\mathrm{n}^{\circ}$ 80-81, pp. 41-47; ÁLVAREZ MARTÍNEZ, María Soledad, "La senda escultórica de los 12 puentes de Vegadeo (Asturias): intervención y/o apropiación del lugar", en Norba. Revista de Arte, n XXXIV, Cáceres, 2014, pp. 273-297. PERMANYER, Lluís, Barcelona, un museo de esculturas al aire libre, Barcelona, Polígrafa, 1991.

6 Un ejemplo significativo puede consultarse en BAZÁN DE HUERTA, Moisés, “El Parque Escultórico del Berrocal en Plasencia. Arte y naturaleza en un centro urbano”, en CHAVES MARTÍN, Miguel Ángel (Dir.), Artes plásticas y Ciudad, Madrid, Grupo de Investigación Arte, Arquitectura y Comunicación en la Ciudad Contemporánea. Universidad Complutense de Madrid, 2015, pp.79-86. 


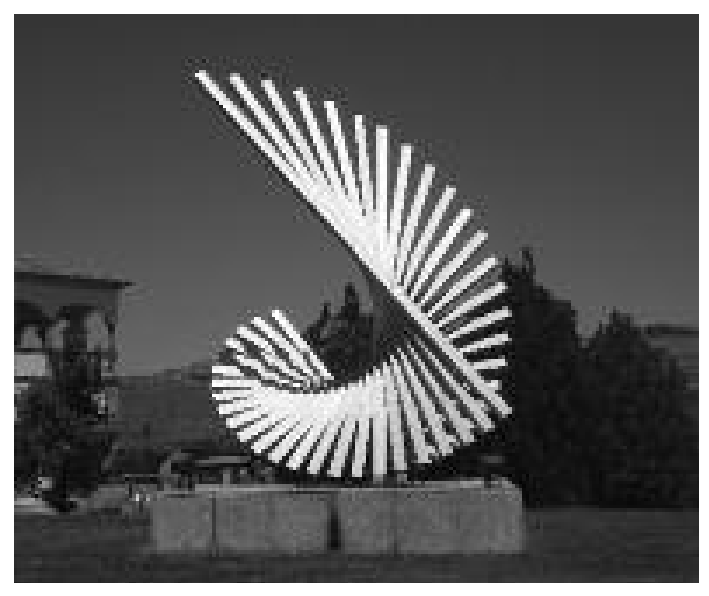

Fig. 1a. Andreu Alfaro. 24 tubos de aluminio. Cáceres. 1978.

tondas, recintos urbanos junto a edificios significativos o museos al aire libre. Pero todas actúan sobre el espacio que las circunda y se convierten inevitablemente en punto de referencia para el ciudadano al integrarse en su entorno. Su máxima aspiración sería constituir dicho espacio en lugar ${ }^{7}$.

Entre los promotores, figuran a la cabeza las instituciones políticas de competencia regional, provincial o municipal, aunque en algún caso participe también el Ministerio de Fomento. En ese sentido, la Ley de Patrimonio Histórico establece la obligación de destinar en los contratos de obras públicas una partida de al menos el $1 \%$ a trabajos de conservación o enriquecimiento del Patrimonio Histórico Español o al fomento de la creatividad artística, con preferencia en la propia obra o en su inmediato entorno ${ }^{8}$. Esta vía, aunque no siempre se respeta, ha generado la erección de algunos de los proyectos que comentaremos y por ello debe valorarse. Por último, cabe consignar el papel de las entidades bancarias (cuando todavía las cajas de ahorro invertían en cultura), a través de premios o certámenes que conllevaban la instalación pública de la obra ganadora.

En este análisis ofrecemos una selección no representativa del panorama global, que no suele alcanzar este nivel. La calidad de la escultura pública extremeña es muy irregular, y cuenta por supuesto con numerosos ejemplos poco afortunados, por la escasa pericia de los auto-

7 Acepción que utilizó con frecuencia Eduardo Chillida y objeto de muy diversas reflexiones. Ver MADERUELO, Javier, "Hacia la definición de un arte público", en Poéticas del lugar..., cit., pp. 17-35.

8 Para paliar en parte la carencia de medios debido a la crisis económica, dicho porcentaje fue ascendido al 1,5\% a finales de 2013.

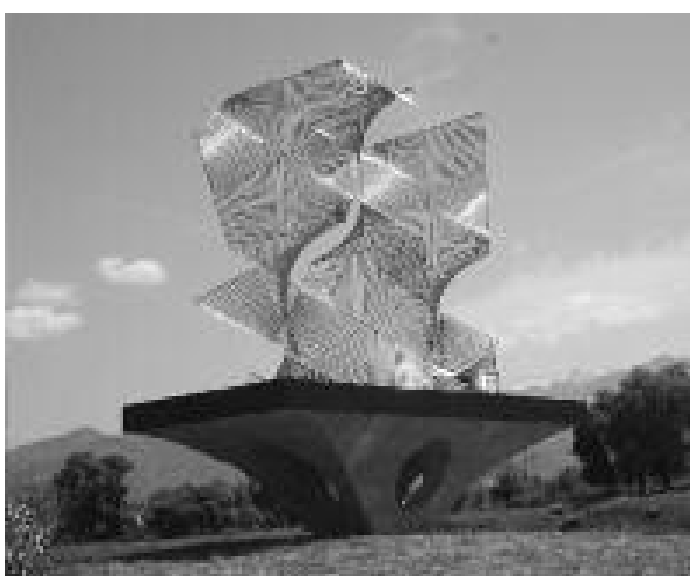

Fig. 1b. Ángel Duarte. E. 26 A. I. (Extremadura). Aldeanueva del Camino. 2005-2006.

res o la falta de exigencia de los responsables ${ }^{9}$. Pero en este campo próximo a la abstracción cabría añadir además las aportaciones de Wolf Vostell, Rufino Mesa, Ricardo Echegaray, Antonio Santonja o artistas asentados en Extremadura como Andrés Talavero, José Luis Hinchado, Miguel Sansón, Eva Domínguez o Antonio Blázquez, que entre otros creadores han dignificado el conjunto aunque ahora no podamos abordarlo.

Abrimos el recorrido con dos de las figuras más importantes de la abstracción escultórica española, representados en Extremadura por creaciones de gran calidad. El primero es Andreu Alfaro (Valencia, 1929-2012). Heredero del constructivismo y vinculado en sus inicios al Grupo Parpalló, pasa de las planchas metálicas a la soldadura del hierro y por fin a la combinación de tubos de acero inoxidable o aluminio de origen industrial, con los que quiere adecuarse a los materiales de su tiempo. A partir de ellos desarrolla un incesante catálogo de creaciones que alcanzan su máxima eficacia en el gran formato y su exposición pública, sobre todo a partir de los años setenta, y que a partir de los noventa compartirán protagonismo con una recuperación sintética de la figuración ${ }^{10}$.

La serie de las generatrices enmarca su obra en Extremadura. En geometría se denomina ge-

9 Cada vez se hacen más necesarias las convocatorias de concursos con jurados competentes, o en su caso comisiones de expertos que puedan asesorar a quienes tienen en su mano la decisión última.

10 Ver, entre la nutrida bibliografía sobre el artista, VV. AA., Alfaro, Madrid, Ministerio de Cultura, 1979; VV. AA., Alfaro, Madrid, Universidad Complutense, 1981; JARQUE, Vicente, Andreu Alfaro. Catálogo Razonado. Vol. I y II, Valencia, IVAM, 2005. Reseñable es la amplia información que recoge el Taller Alfaro: http://www.andreualfaro.com/es/. 
neratriz a una línea que al desplazarse sobre una directriz produce una superficie. En el caso de Alfaro las líneas son otros tantos tubos yuxtapuestos que, girando en torno a un eje recto (o curvo), engendran superficies que dan lugar a una estructura tridimensional. Algunas de ellas generan paraboloides, y ello conecta parte de su producción con la de Ángel Duarte que pronto veremos.

24 tubos de aluminio ( $4 \times 3 \times 3,2 \mathrm{~m}$ ), creada en 1978, llegó a la región en 1982 desde el taller del artista. Fue montada por el propio Alfaro como uno de los autores invitados fuera de concurso al II Premio Cáceres de Escultura. El certamen cerraba tres convocatorias previas anuales que alternaron pintura y escultura ${ }^{11}$. La obra de Alfaro sería adquirida por la Diputación para emplazarse en la Institución Cultural El Brocense, primero en el claustro, donde se encontraba algo constreñida, y luego con fortuna en el exterior, abriéndose al espacio y constituyéndose como signo de identidad del recinto.

La evidencia del título puede hacer pensar en un concepto meramente acumulativo, que conviene obviar por cuanto la obra sólo adquiere valor al percibirse en conjunto, como integración armónica de todas sus piezas. De esta forma, en su condición lineal, giratoria y centrífuga, desarrolla un continuum ascensional perceptivamente móvil. El propio Alfaro señala que sus esculturas tienen una cierta cualidad cinética, ya que dan libertad al espectador para hacerlas cambiar a voluntad con su propia trayectoria ${ }^{12}$. Esa voluntad comunicativa es otra de las constantes del artista y marca su apuesta por un arte público, positivo y e integrador, capaz de actuar sobre su entorno.

Ángel Duarte (Aldeanueva del Camino, Cáceres 1930 - Sierre-Sion, Suiza, 2007) es uno de los artistas extremeños con mayor proyección internacional. Tras su formación como pintor en $\mathrm{Ma}-$ drid, marcha a París, siendo cofundador del Equipo 57, grupo clave para entender la abstracción geométrica española. Desde una actitud crítica con la situación de la cultura y el mercado artístico, sus aportaciones teóricas y prácticas sobre la inter-

11 VV. AA., II Premio Cáceres de Escultura, Cáceres, Diputación Provincial, 1982. Estos premios fueron un auténtico acontecimiento en la región, al reunir a las principales firmas del arte nacional en un copioso despliegue de estilos y tendencias. Sobre la escultura concreta de Alfaro, ver LOZANO BARTOLOZZI, María del Mar, Escultura pública..., cit., pp. 67-69.

12 CIRICI PELLICER, Alexandre, "Reflexión sobre Alfaro", en VV. AA., Alfaro, Madrid, Universidad Complutense, 1981 , p. 99. actividad del espacio plástico en la pintura o la escultura y el diseño de muebles se desarrollaron dentro del grupo hasta su disolución. Desde Suiza en los años sesenta, primero adscrito a la NouvelleTendance y el Grupo Y, después en solitario, dio continuidad a sus investigaciones sobre estructuras modulares basadas en el paraboloide hiperbólico, y plasmadas en relieves y esculturas exentas, algunas dispuestas en lugares públicos desde los años setenta. La pintura y las experiencias con efectos ópticos marcarán también las décadas siguientes ${ }^{13}$.

Fue recuperado para la Comunidad Autónoma en el citado II Premio Cáceres de Escultura de 1982 y diez años después con una gran antológica en la capital altoextremeña. Esta labor de reconocimiento culminó con la concesión de la Medalla de Extremadura en 2001 y la iniciativa de la Junta de Extremadura para erigir una escultura de gran formato en la región. Bajo el título E. 26 A. I. (Extremadura), ésta se obtuvo a partir de la ampliación de un modelo previo, utilizando $780 \mathrm{~m}$. de tubo de acero inoxidable de $22 \mathrm{~mm} \emptyset$ hasta alcanzar unas medidas globales de 5,1 x 7,2 x 3,3 m. La escultura resultante consta de 36 paraboloides hiperbólicos, 108 directrices y 612 generatrices ${ }^{14}$. El paraboloide es una superficie reglada que posibilita crear superficies alabeadas a partir de líneas rectas, y Duarte lo ha utilizado en infinitas variantes para desarrollar un insólito despliegue de soluciones, que sin abandonar la rigurosidad modular apelan también a la sensibilidad retiniana y el cinetismo.

La escultura fue instalada en 2006 en la rotonda de acceso desde la Autovía A-66 a la localidad natal del artista ${ }^{15}$. Para ello se construyó un aerodinámico pedestal de hormigón con núcleo perforado diseñado por el propio Duarte. Lamentablemente un fuerte vendaval consi-

13 Entre otros textos, ver sobre el artista: VV. AA., Equipo 57, Madrid, MNCARS, 1993; VV. AA., Equipo 57 (19571962), Madrid, Turner-Junta de Andalucía, 2007; CANO RAMOS, Javier y Otros, Ángel Duarte, Cáceres, Junta de Extremadura, 1992; CANO RAMOS, Javier y Otros, Ángel Duarte, Badajoz, Fundación Caja Badajoz, 2001; CANO RAMOS, Javier, Ángel Duarte, más allá del Equipo 57, Badajoz, Ayuntamiento de Don Benito-Caja de Badajoz, 2008.

14 Hemos tenido acceso a las precisas tablas, desviaciones y cálculos realizados por Duarte; también al diseño del pedestal y fotografías de la compleja instalación. Agradecemos a Javier Cano Ramos el material facilitado.

15 ÍCARO PRESS, "La escultura de Ángel Duarte ya preside la Ruta de la Plata”, El Periódico Extremadura, 27-42006; REDACCIÓN, “Ángel Duarte ya tiene una obra propia en su Aldeanueva natal”, Hoy, 28-4-2006. 


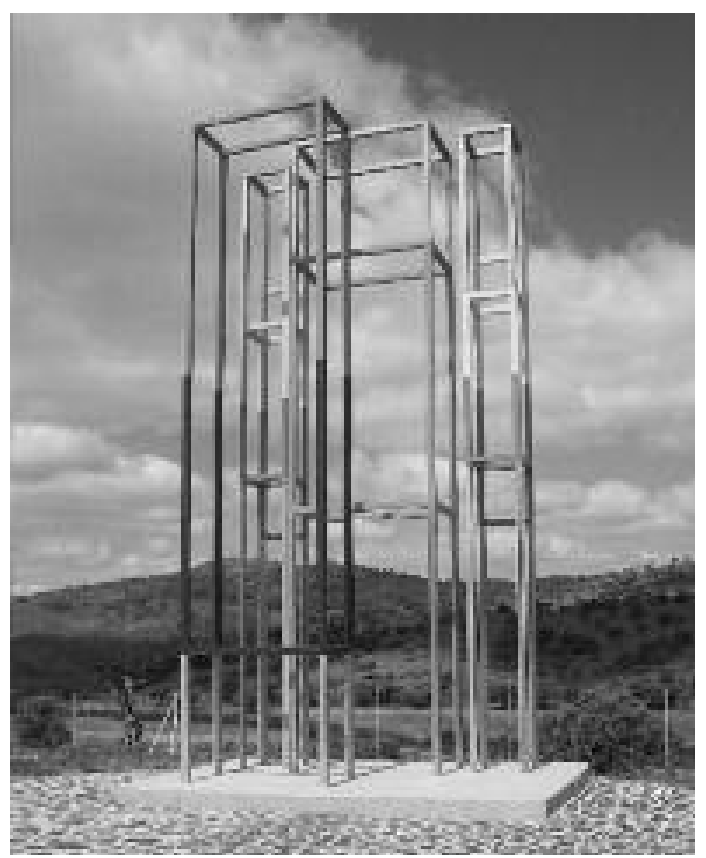

Fig. 2a. Florentino Díaz. Casa cómoda para mirar el paisaje. Autovía A-66 Cáceres-Plasencia. 2004.

guió desprender la escultura de su soporte y causarle daños, por lo que ha tenido que ser reparada y se reinstalará en 2016 en el propio municipio de Aldeanueva del Camino ${ }^{16}$.

Dos nuevas obras de autores extremeños dan continuidad a este panorama. Ambas comparten una cierta identidad formal, como estructuras geométricas verticales que se sirven del metal y el color para afirmar su autonomía plástica; están ubicadas en vías de tráfico y surgen por la aplicación del uno por ciento cultural.

Florentino Díaz (Fresnedoso de Ibor, Cáceres, 1954) trabaja habitualmente en Madrid. Allí, tras formarse en círculos alternativos al ámbito más académico, se dio a conocer en la década de los ochenta, primero en la pintura para en los años noventa explorar progresivamente el campo tridimensional. En su trayectoria son habituales el uso de materiales reciclados y la combinación escultórica de estructuras metálicas con tiras de caucho y otros elementos. El artista recibió el Premio Extremadura a la Creación en el año $2000^{17}$.

Buena parte de su discurso está ligado a la reflexión sobre la cotidianeidad, el hogar y la

16 La Junta de Extremadura encargó previamente a Duarte otra obra de $4 \mathrm{~m}$. que fue expuesta en la Expo 92 de Sevilla, para ubicarse finalmente ante la fachada del $\mathrm{Mu}-$ seo Extremeño e Iberoamericano de Arte Contemporáneo en Badajoz.

17 Ver VV. AA., Plástica Extremeña, Badajoz, Fundación Caja de Badajoz, 2008, pp. 426-427.

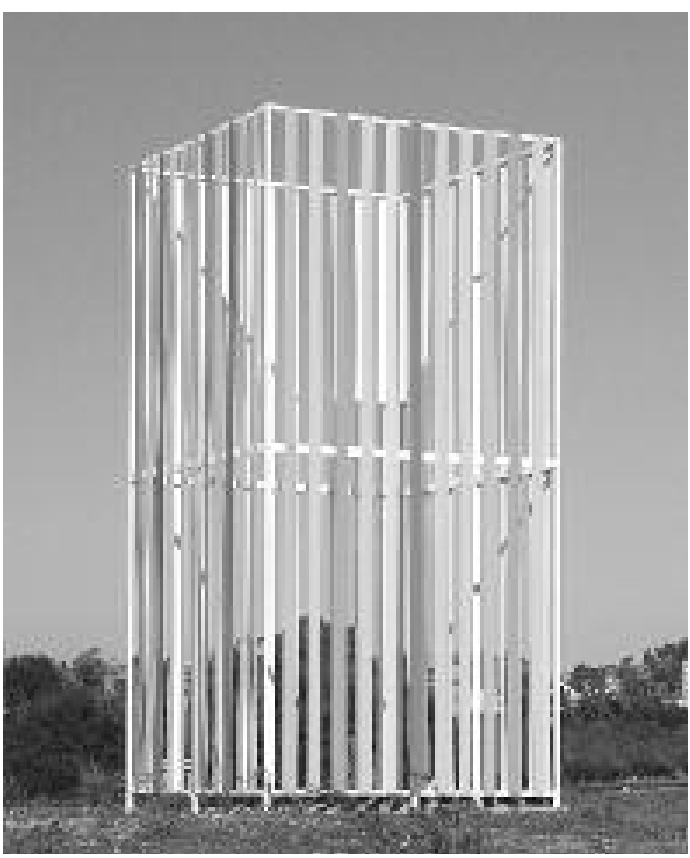

Fig. 2b. Julián Gómez. Estructura de color. Cáceres. 2004.

casa, entendiéndola como un espacio arquetípico o simbólico, y a ello no es ajena su creación Casa cómoda para mirar el paisaje, construida en 2004 con acero inoxidable y unas dimensiones de 11,5 x 4,2 x 2,8 m. para ser alzada en la Autovía de la Plata. En ella sustituye la habitual pared de la galería, creada por el hombre, por un espacio abierto a la naturaleza. Se ha hablado así de un paisaje domesticado ${ }^{18}$, pero además la paradoja implícita en el título es que su instalación no facilita un acceso que permita utilizarla como lugar de parada, reposo o mirador. Ubicada en medio de una prolongada recta, ha de contar por tanto con un espectador cinético, que únicamente podrá obtener cierta delectación formal por el atractivo juego cromático que la anima. Y ello porque sólo una observación detenida permite descubrir "camufladas" ciertas referencias figurativas. Se trata en realidad de sucintas mesas, sillas y armarios que se disponen tanto en vertical como invertidos, a modo de imagen especular. Estructuras neutras grises, en cuatro módulos independientes pero coordinados, contribuyen al sostén de los distintos elementos, que de esta forma parecen flotar en el aire.

18 LOZANO BARTOLOZZI, María del Mar, “¿Fin del arte o fusión de lo diferente? El arte en la frontera de la postmodernidad", en LACARRA DUCAY, Ma del Carmen (Coord.), Arte de épocas inciertas: de la Edad Media a la Edad Contemporánea, Zaragoza, Institución Fernando el Católico, 2009, pp. 353 y 373. 


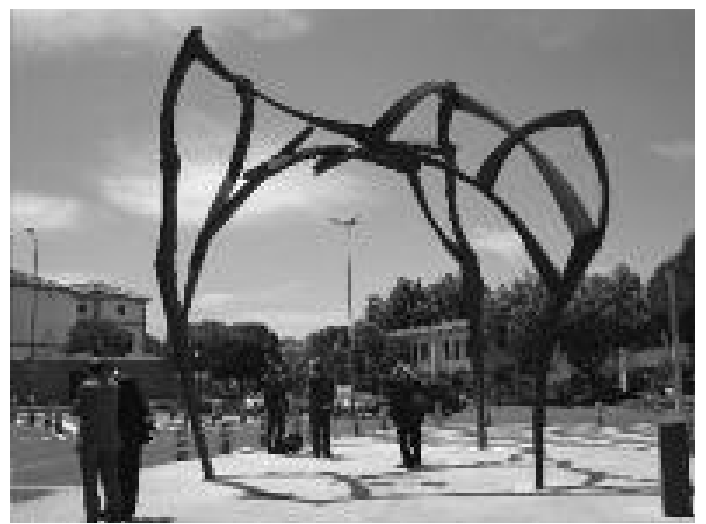

Fig. 3a. Mar Solís. El espacio recorrido. Plasencia. 2008.

La siguiente escultura es del artista Julián Gómez Sánchez (Cáceres, 1966), muy activo en la primera década del siglo, aunque actualmente comparte su labor creativa con la restauración. El suyo ha sido siempre un lenguaje abstracto, que alterna la pintura y la escultura en series de tendencia constructiva, minimalista u óptica, con referencias a Mondrian, Albers, Judd, Le Witt o Rothko. Trabaja con módulos geométricos que articulan variaciones direccionales y cromáticas. La frecuente inclusión de pantallas de metacrilato blanco difumina sus formas bidimensionales, haciéndolas flotar en un espacio inmaterial pleno de sutilezas. En otros casos combina vibrantes campos de color por medio de ceras. Y finalmente experimenta con el metal y el relieve para organizar esquemas reticulares en busca de un equilibrio compositivo.

Esta última línea de trabajo es la que contemplamos en su Estructura de color, instalada en 2004 en una nueva rotonda a la salida de Cáceres en dirección a Badajoz. Fue financiada por la Junta de Extremadura y gestionada a través de la galerista María Llanos. Dos cubos de 3 metros de lado, superpuestos en altura para configurar una sola pieza, se alzan en un espacio bien escogido. Los delimitan láminas verticales de hierro galvanizado, tratado con esmalte antióxido. Su policromía despliega una especie de arco iris ante el paisaje abierto de la dehesa extremeña.

Esa finalidad meramente estética es la confesada por el artista, que en ese momento elaboraba composiciones similares en piezas de pared. Combina en su obra la rigurosidad geométrica con un lirismo colorista y grato que busca transmitir armonía al espectador. Su apuesta puede ponerse en diálogo con los montajes cromáticos y ópticos de Yaacov Agam o Lian Gillick ${ }^{19}$.

19 VV. AA., Plástica Extremeña, cit., pp. 462-463.

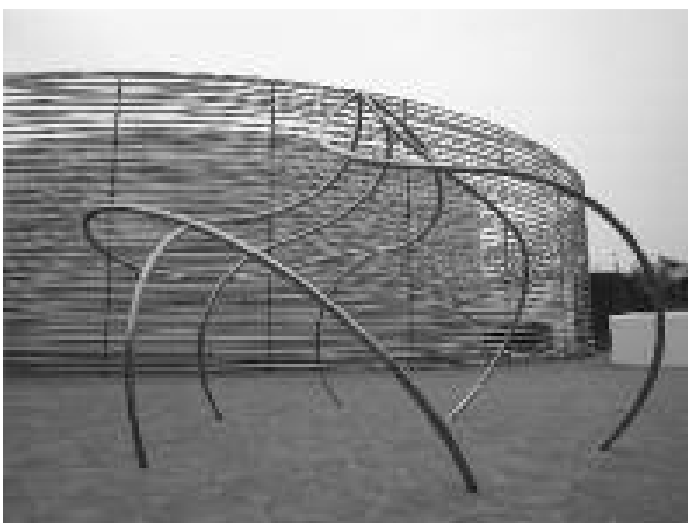

Fig. 3b. Blanca Muñoz. Eclíptica. Badajoz. 2006.

En un nuevo bloque hemos querido agrupar dos creaciones firmadas por mujeres. No tanto porque encarnen una tendencia de género con rasgos distintivos, sino para consignar que su presencia es relevante y ha dado lugar a esculturas de gran calidad. Ambas en su trayectoria profesional utilizan la abstracción y dialogan con el espacio o el muro; y coinciden en sus obras extremeñas en la liviandad formal, adoptar estructuras de recinto y evocar determinadas referencias conmemorativas.

El primero es un trabajo de Mar Solís (Madrid, 1967) y está instalado en Plasencia. Su proceso de gestación merece conocerse por sus diversas implicaciones. En Plasencia nació Inés de Suárez, compañera de Pedro de Valdivia y figura destacada en el proceso de la conquista y fundación de Santiago de Chile. El municipio deseaba rendirle homenaje, y un primer proyecto surgió en el marco de las celebraciones del V Centenario del Descubrimiento en 1992, aunque el concurso convocado no llegaría a culminarse. La idea se retomó en 2006, coincidiendo con los quinientos años de su nacimiento y la presentación de la novela de Isabel Allende Inés del alma mía, centrada en su biografía. La propia escritora estaba dispuesta a cofinanciar la estatua sobre un proyecto de la escultora chilena Mónica Bunster, ideado ya en 1988; pero tampoco la iniciativa encontró salida ${ }^{20}$.

La oportunidad surge de nuevo en 2007 con la II edición del Premio Internacional de Escultura, auspiciado por Caja de Extremadura. El cer-

20 A. S. 0., "Fallido monumento", Hoy, 31-5-2006; REDACCIÓN, “Una escultura de Inés de Suárez irá en Los Alamitos”, El Periódico Extremadura, 21-6-2006; M. R. REY, "Isabel Allende presenta Inés del alma mía en Plasencia", El Periódico Extremadura, 19-9-2006; SIN FIRMA, "Plasencia. Una calle y un colegio”, Hoy, 23-2-2007; SIN FIRMA, "Turismo reactiva la hermandad pendiente con Cuenca y Santiago”, Hoy, 2-1-2010. 
tamen conllevaba la erección pública de la obra ganadora $^{21}, \mathrm{y}$ a instancias del ayuntamiento se orientó hacia la conmemoración de la valerosa dama placentina. Ni muchos de los participantes en el concurso ni el propio Jurado se vieron condicionados por la temática, y de hecho la imagen elegida no parece inspirada por el personaje, aunque pueda entenderse como lugar de tránsito entre dos continentes ${ }^{22}$.

Así nace El espacio recorrido, una imponente estructura de 7 metros en acero corten instalada en 2009 en la avenida de la Cañada Real, un enclave espacioso y visible que facilita su entidad como lugar de encuentro. Y es que la artista la concibe como un recinto, un espacio sutilmente delimitado, aunque abierto, al sustentarse en sólo tres livianos puntales filiformes. La escultura invita a ocupar su interior y transitarlo, y desde dentro el espectador descubrirá las sugerentes tramas de la cubierta y las sombras que éstas generan en el suelo. Esta concepción espacial es una constante en la autora, que en otras series también hace dialogar sus formas con el muro. Utiliza para ello piezas curvas de sección cuadrada que se agrandan en su extremo hasta entrar en contacto con otras; a partir de esa zona de inflexión se produce un cambio de rumbo que va configurando una secuencia multidireccional. El resultado es asimétrico e imprevisto, trazado con una especie de caligrafía gestual que rememora formas orgánicas y se revela más intuitiva que geométrica, aportando calidez y expresividad al conjunto.

Su elección fue en definitiva una apuesta valiente, que ha vencido los recelos iniciales de la población para integrarse en el espacio urbano. Su autora, formada en la Universidad Complutense de Madrid, ha consolidado con hitos como éste una sólida trayectoria con un lenguaje plástico inconfundible ${ }^{23}$.

21 Con un presupuesto de $18.000 €$ para el autor y 70.000 para la ejecución de la obra.

22 Formaron el Jurado Juan Manuel Bonet, Julio López Hernández, Martín Chirino, Pedro Terrón y Moisés Bazán de Huerta. Premio Internacional de Escultura de Caja de Extremadura. Segunda Edición. Exposición de maquetas seleccionadas, Plasencia, Caja de Extremadura, 2008; RODRÍGUEZ, Raquel, “Caja Extremadura otorga su premio de escultura a la madrileña Mar Solís”, El Periódico Extremadura, 18-7-2008; ARMERO, Pilar, "Solís recibe el II Premio Internacional de Escultura de la Caja de Extremadura", Hoy, 28-9-2008; S. F., "Plasencia estrena la obra escultórica El espacio recorrido", Hoy, 2-6-2009.

23 Cabe destacar entre sus exposiciones: Estancias (2002); Encuentros con la pared (2004); Raices del aire (2010); El cielo abierto (2008, 2010); La línea, la Curva, la Elipse (2012); Dibujar, Transformar (2012) o La sustancia del aire
Similares parámetros observamos en Blanca Muñoz (Madrid, 1963), otra de las creadoras destacadas en el panorama artístico actual ${ }^{24}$. Su escultura Eclíptica de 2006 surge por la aplicación del uno por ciento cultural, ya que está vinculada a la construcción del Palacio de Congresos de Badajoz, de los arquitectos José Selgas y Lucia Cano. El singular edificio se alza donde estuvo la antigua plaza de toros, y condicionado por ello adopta una estructura circular. Durante la guerra civil en dicha plaza se produjeron un gran número de asesinatos, y éste hecho debía ser rememorado por la escultura, a los 70 años de iniciarse el conflicto. Así que de nuevo una obra abstracta ha de asumir connotaciones simbólicas, y Blanca Muñoz lo resuelve con una propuesta site specific de alto contenido poético.

La fecha prevista para la inauguración era un 14 de agosto, coincidente con la entrada de las tropas franquistas en Badajoz, aunque tuvo que posponerse por razones burocráticas. El dato es relevante, porque según la autora en torno a esa fecha la escultura proyecta en el suelo una galaxia espiral dentro de los límites de su base, equiparable también a los pétalos de una flor. De esta manera, la referencia solar del título cobra un nuevo sentido al dibujar con la sombra el motivo evocado. No es fácil comprobar el fenómeno en su enclave real, aunque sí se percibe con nitidez en la versión de menor formato expuesta con posterioridad en diversas galerías.

La recepción de la obra fue diversa por parte del público, como revelan los comentarios en prensa. Se cuestionó cierta frialdad y se reclamaba una placa que explicara la intención política del proyecto. Pero supo apreciarse su incuestionable calidad formal, que ocupa un espacio de 5,5 x 8,5 × $7 \mathrm{~m}$. por medio de barras de acero inoxidable de sección circular ${ }^{25}$. El conjunto asume una forma helicoidal que asciende como una llama en sinuosas y elegantes curvas que se afirman con limpieza. Estamos de nuevo ante un espacio transitable, que dialoga además de forma fluida con el edificio al que acompaña.

(2013). Amplia información puede obtenerse en su WEB: http://marsolisescultura.blogspot.com.es/.

24 Su producción se desarrolla también en el campo de la obra gráfica. Sobre la excelente trayectoria de la artista, que trabaja con la Galería Marlborough, recomendamos consultar su cuidada WEB: http://www.blancamunoz.com/.

25 LEITON, Guadalupe, "La escultura por la guerra civil se coloca a final de mes", El Periódico Extremadura, 8-9-2006; BARRADO TIMÓN, Mercedes, "Inaugurada en Badajoz la escultura en memoria de las víctimas de la guerra”, Hoy, 23-9-2006; GARCÍA, S., "La escultura de Ronda del Pilar proyecta una flor”, El periódico Extremadura, 15-8-2007; R. R., "Homenaje con forma de flor”, Hoy, 15-8-2008. 


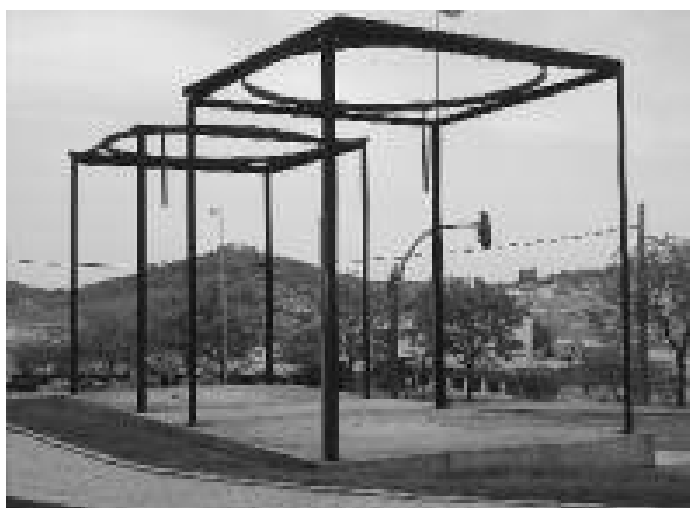

Fig. 4a. Nacho Criado. Monumento a la Paz y la Concordia. Cáceres. 2004-2005.

La conversión del espacio en lugar se revela como uno de los motores desencadenantes de la escultura abstracta extremeña. Volvemos a apreciarlo en un proyecto que tiene además estrecha relación temática con el anterior. El fusilamiento del alcalde y un gran número de republicanos durante la guerra civil en el Paseo Alto de Cáceres, junto al cuartel Infanta Isabel, es el hecho que genera esta nueva obra, propiciada en 2004-2005 por la erección de un residencial. La recuperación de la memoria histórica se realiza una vez más desde una mirada positiva, sin el lastre del rencor, concibiéndose como un $\mathrm{Mo-}$ numento a la Paz y la Concordia ${ }^{26}$ que, en palabras de su autor, "es un espacio de diálogo y encuentro para todo el que quiera descansar bajo esta construcción".

Y el autor no es otro que Nacho Criado (Mengíbar, Jaen, 1943 - Madrid, 2010), uno de los pioneros del arte conceptual en España, con una sugestiva carrera que mereció poco antes de su prematura muerte la Medalla de Oro al Mérito en las Bellas Artes (2008) y el Premio Nacional de Artes Plásticas (2009) ${ }^{27}$. Artista difícil de encuadrar, por la variedad y singularidad de sus acciones, ha reflexionado sobre conceptos como el tiempo, el cambio, la materia, la dialéctica de la destrucción o el devenir, a partir de proyectos e instalaciones con alto valor procesual y entendiendo siempre el arte como generador de ideas ${ }^{28}$.

26 Utilizamos el término "monumento" porque fue así como se dio a conocer en su difusión pública. Ver LUCEÑO, Lola, "Una escultura apaga los ecos de la guerra", El Periódico Extremadura, 1-7-2005; FERNÁNDEZ, Juan Domingo, “Arte y jubilación”, Hoy, 28-1-2011.

27 SIN FIRMA, "El escultor Nacho Criado, Premio Nacional de Artes Plásticas”, $A B C$, 5-11-2009; LORENCI, Miguel, "El arte nómada de Nacho Criado", $A B C$, 4-5-2012.

28 Ver, entre otros textos, MARSET, Juan Carlos y CASTRO FLÓREZ, Fernando, Nacho Criado. La idea y su puesta en

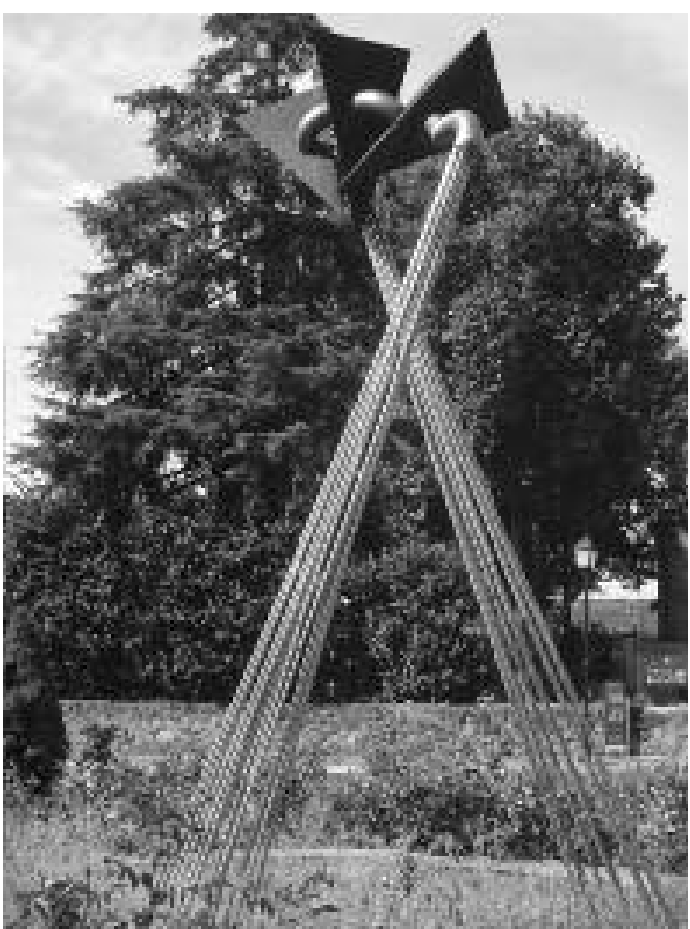

Fig. 4b. César David. Tres encuentros. Jarandilla de la Vera. 2000.

En esta obra Criado aplica una concepción minimalista. Son dos pórticos geminados de acero corten que adoptan la forma cúbica; en ellos hay sendas circunferencias inscritas en la parte superior, a modo de bóvedas que marcan el tránsito entre lo terreno y lo celeste, proyectando su sombra en diálogo con los círculos incisos en el basamento de granito gris. Las estructuras evocan a su vez las casas fuertes del recinto monumental cacereño, pero lejos de mostrar muros o espacios cerrados, se conciben transparentes, con un extremo esencialismo formal. Aunque una placa ilustra en este caso el mensaje pretendido, la apuesta por un arte abstracto despojado de cualquier información hace que la obra no llegue a conectar con los habitantes de Cáceres y pase desapercibida, pese a constituir un mirador privilegiado a la ciudad.

La vertiente más expresiva de este conjunto de obras la encarna César David Montero (Navasfrías, 1965), salmantino de origen y formación, aunque reside y trabaja en Cáceres. Vinculado a una empresa familiar de hierros industriales, la estrecha relación con este metal ha definido su trayectoria hasta dominar el medio con auténtico virtuosismo. Con el hierro di-

escena, Sevilla, Sibilina, 1996; CASTRO FLÓREZ, Fernando, Nacho Criado. La voz que clama en el desierto, Madrid, Fundación Argentaria, 1998; GUIDIERI, Remo y Otros, Agentes colaboradores, Madrid, MNCARS, 2012. 
buja en el espacio, delimita superficies y articula estructuras que exploran efectos cinéticos, tensiones compositivas, suspensiones, recintos y el diálogo entre formas contrapuestas ${ }^{29}$. Interesado por la adecuación entre idea, forma y espacio, sus investigaciones se han trasladado con frecuencia al ámbito instalativo y monumental ${ }^{30}$. Conviene citar en este sentido su Fuente del tiempo para Malpartida de Cáceres (2002), que muestra paralelismos conceptuales y formales con la obra que ahora nos ocupa.

Tres Encuentros (2000, 6 × 2 × 1,2 m) es de nuevo un proyecto site specific, cuya génesis se vincula con un lugar y hechos concretos. Recupera una escala en la ruta que el Emperador Carlos V realizó en su viaje al Monasterio de Yuste, retirándose para dejar el gobierno en manos de su hijo Felipe II. Por eso la rotonda en que se alza la escultura dialoga con el castillo-palacio de los Condes de Oropesa, hoy Parador de Turismo, donde el rey se hospedó antes de trasladarse a su residencia definitiva.

El concepto de tránsito, de viaje, se transmite por medio de dos grandes soportes que se desplazan en actitud de caminar, y para los que César David aprovecha de forma inteligente los principios de su serie Andarinas, piezas con patas metálicas que se mueven realmente en el espacio. Aquí cabría mejor hablar de un cinetismo virtual, por cuanto sólo se sugiere esa idea, cuyo efecto se acentúa al rodear la rotonda en auto. El artista quería plasmar un homenaje a los paisanos que con tantas dificultades atravesaron la Sierra de Tormantos portando en parihuelas al emperador.

Los dos soportes están conformados por varillas de acero inoxidable, más abiertas en su contacto con el suelo y agrupadas en el extremo superior hasta encajarse en sendos tubos curvos. Esa estructura sostiene a su vez tres cuerpos piramidales invertidos de acero corten que sólo en forma simbólica apuntan la presencia del emperador. Encarnan los poderes que Carlos V deja atrás en su retiro extremeño: la iglesia, España y Europa. Por supuesto este significado resulta ajeno al espectador, pero da sustento teórico a

29 VV. AA., Plástica Extremeña, cit., pp. 416-417.

30 Cabe destacar intervenciones como Compositorio en el Museo Vostell Malpartida (2001); Espacio entre puertas rojas, dentro de la muestra Recorridos (2004); o el espectacular ciclo expuesto en el barrio antiguo de Cáceres en 2009. Ver BAZÁN DE HUERTA, Moisés, Recorridos. Esculturas e Instalaciones, Badajoz, Editora Regional de Extremadura, 2004, pp. 27-41 y HUBERT LÉPICOUCHÉ, Michel y BAZÁN DE HUERTA, Moisés, Deconstrucción. Naces, Eres, Mueres, Tierra, Cáceres, Junta de Extremadura, 2009. la propuesta e incluso habría sido más eficaz de haber podido culminarse el programa iconográfico que completaba el ciclo con otras dos instalaciones en Tornavacas (elaborada por Florentino Díaz) y Cuacos de Yuste.

Y abordamos ya un último apartado. La creación de parques escultóricos o museos de escultura al aire libre ${ }^{31}$ ha sido un factor determinante en la asunción con naturalidad de propuestas de vanguardia en el enclave urbano ${ }^{32}$. La pluralidad de estilos y la convivencia de las obras en un recinto concreto disminuyen el efecto de rechazo que puede mostrar parte de la población ante proyectos aislados. Esos requisitos los cumple el Museo de Escultura al Aire Libre de Cáceres, que fue fundado en 1997 a instancias municipales y en aras de ofrecer alternativas contemporáneas al extraordinario patrimonio monumental que brinda la ciudad ${ }^{33}$. Su promotor fue el escultor onubense Pepe Noja, avalado por iniciativas previas similares en Aracena, Huelva y Alcalá de Henares. El resultado es un conjunto de 27 piezas de gran o medio formato, instaladas en el recinto vallado del Parque del Príncipe, entre árboles y siguiendo el eje de un canal de agua. Es una colección heterogénea, que proviene de los contactos del pro-

31 Sobre la ambivalencia terminológica y práctica de estos términos ver LORENTE, Jesús Pedro, "Museos de escultura en espacios urbanizados: paradigmas de su desarrollo en España” en Arte público hoy. Nuevas vias de consideración e interpretación crítica. Actas del Congreso Internacional de Criticos de Arte 2009, Valladolid, AECA/ACYLCA, 2010, pp. 127-148; ampliado en “¿Qué es un museo de escultura al aire libre? Consideraciones sobre la denominación de colecciones artísticas musealizadas en el espacio público", en BAZÁN DE HUERTA, Moisés (Coord.), Periferias escultóricas. Rev. HUM 736, $\mathrm{n}^{\circ} 18$, pp. 71-84. Como marco general y en su relación con la naturaleza puede consultarse BLÁZQUEZ, Jimena y Otros, Parques de esculturas. Guía de Europa. Arte y Naturaleza, Vejer de la Frontera, Fundación NMAC, 2006.

32 Paradigmática fue la creación del Museo de Escultura al Aire Libre instalado en el Paseo de la Castellana en Madrid a fines de los setenta, que abre esta fructífera vía. Ver RIVAS, María José y SALAS, Eduardo, Guía del Museo de Escultura al Aire Libre de La Castellana, Madrid, Ayuntamiento, 1995. La evolución posterior de estas iniciativas ha ido ramificándose en diversas tipologías y enclaves. Colecciones unificadas establecidas en instituciones públicas o recintos de museos; campus (Leganés, Valencia...); programas urbanos en capitales destacadas como Barcelona, Gijón, Vigo y otras muchas; parques escultóricos en entornos naturales (Montenmedio, Isla de esculturas, Parcart, Arte y Naturaleza...); o bien en colecciones dispersas, como la que atesora RENFE.

33 En el ámbito extremeño su protagonismo lo comparte el pionero Museo Vostell Malpartida, que cuenta con avanzadas creaciones de vanguardia en un impresionante paraje natural. Y en menor medida el Parque Escultórico del Berrocal, también monográfico, instalado en Plasencia. 


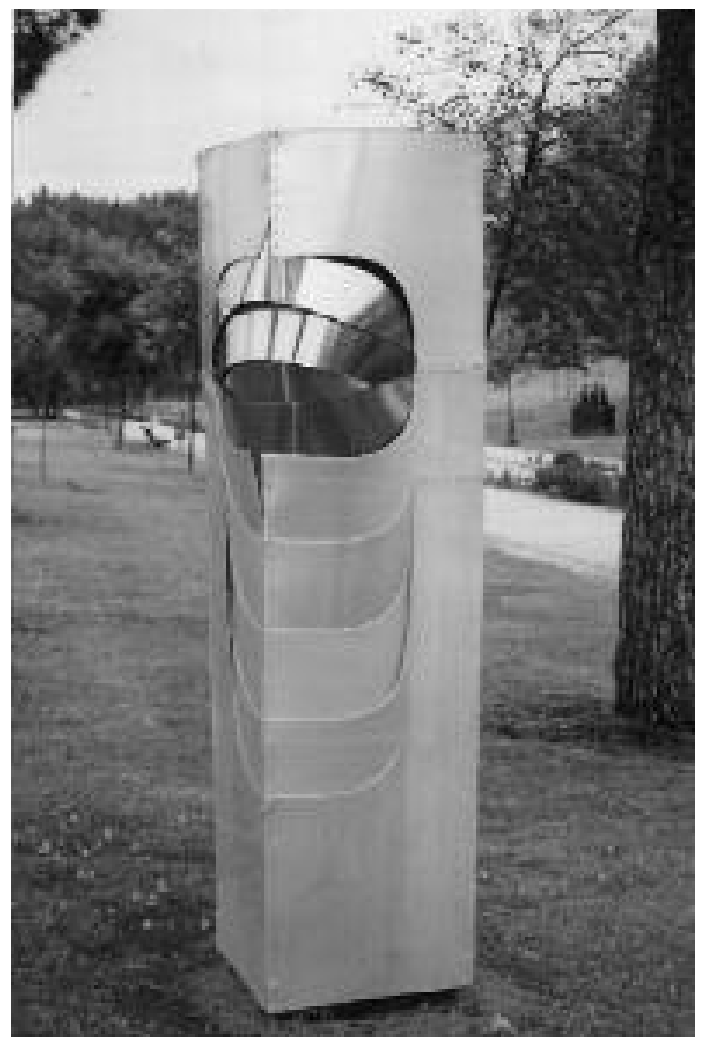

Fig. 5a. Amadeo Gabino. Argos XII. Cáceres. 1988.

motor con los diferentes artistas. Éstos cedieron sus obras a bajo coste para integrarse en un ambicioso programa, que no llegó a cumplir los objetivos previstos en cuanto a número. Aunque la colocación es un tanto aleatoria, cuida el comportamiento de los volúmenes sobre el terreno y busca una alternancia entre los materiales y los diversos lenguajes plásticos, que van desde el realismo a la abstracción. Reúne así hasta tres generaciones de escultores, españoles e iberoamericanos, con un nivel medio notable y algunos ejemplos de gran entidad. Dentro de la abstracción se encuentran las firmas de Amadeo Gabino, Feliciano Hernández, José Luis Sánchez, Luis Caruncho, Lorenzo Frechilla, Teresa Eguíbar, Amador Rodríguez, Nassio Bayarri, José Miguel Utande, Manuel Ferreiro, Carlos Evangelista, Xuxo Vázquez y el mismo Pepe Noja ${ }^{34}$. Del conjunto seleccionamos dos obras que sirven a su vez para culminar el estudio.

Amadeo Gabino (Valencia, 1929 - Madrid, 2004) se encuentra entre esa nómina de creadores que han logrado generar un lenguaje formal pro-

34 Ver NOJA, Pepe y Otros, Museo de Esculturas al Aire Libre. Parque del Príncipe, Cáceres, Ayuntamiento de Cáceres, 1998; y BAZÁN DE HUERTA, Moisés, "El Museo de Escultura al Aire Libre de Cáceres”, en Norba-Arte, $n^{\circ}$ XXII-XXIII, Cáceres, 2003, pp. 261-292.

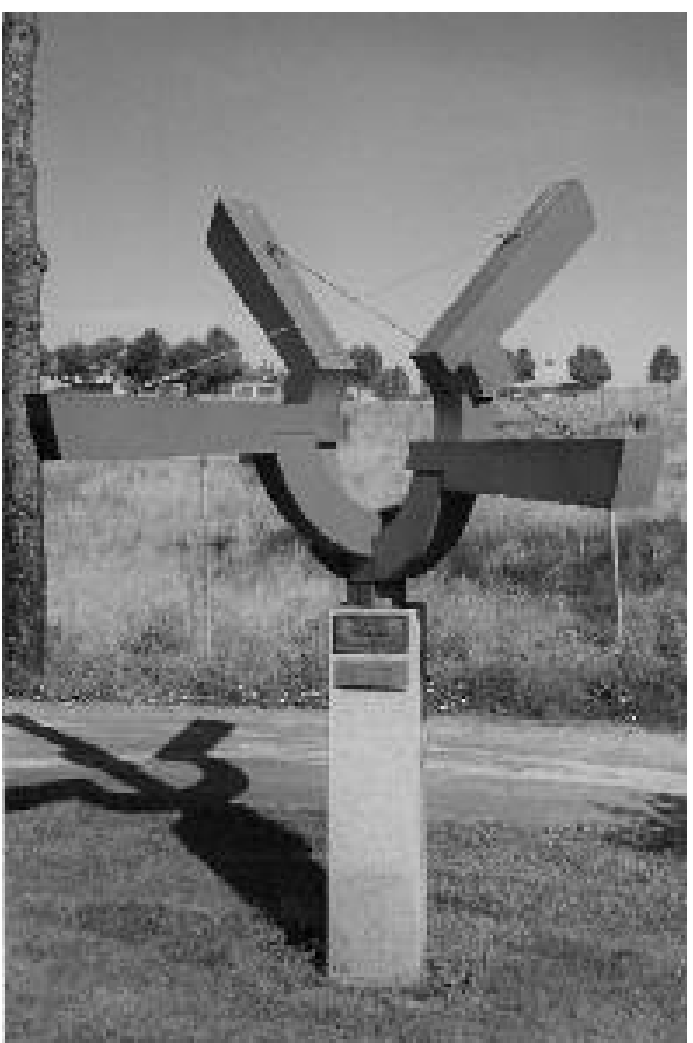

Fig. 5b. Feliciano Hernández. Tensión cruzada. Cáceres. 1990.

pio, y a través del mismo granjearse un lugar importante en la escultura española contemporánea. Desde los últimos años sesenta había consolidado ya su línea creativa mediante la superposición de planchas metálicas curvas unidas por remaches o puntos de soldadura. Utilizando hierro, acero inoxidable o aluminio, sus piezas alternan superficies mates y pulidas, con estructuras concéntricas y solapadas que, a modo de armadura, enmarcan un núcleo interno generador. Aplica este proceso a relieves y esculturas exentas, alcanzando una dimensión considerable en el gran mural para la central eléctrica de Castrelo. En paralelo a la escultura en metal, ha cultivado también el grabado y el diseño. Será en los años noventa cuando asistamos a una notable evolución en sus trabajos, tendentes entonces a una mayor síntesis formal.

Gabino ordena su producción en series, bautizadas con títulos disémicos que remiten tanto al mundo cósmico como mitológico. Así, por medio de cubos o prismas va desplegando todo un repertorio de formas a partir de similares principios constructivos ${ }^{35}$. Argos XII (acero inoxi-

35 Ver GARCÍA TIZÓN, Antonio, Amadeo Gabino, Madrid, Ministerio de Educación y Ciencia, 1972; GIRALT-MIRACLE, Daniel, Amadeo Gabino. Notas en torno a su obra, 
dable, 2,5 x 0,6 x 0,6) es el nombre de la escultura escogida para mostrarse en Cáceres. Pertenece a una saga iniciada en 1987, con pautas afines a la serie Estela de Venus, conformada ya en los años setenta. Su estructura en este caso es más vertical que cúbica, y su peculiaridad que los componentes que parecen emerger desde el núcleo no se adaptan a los lados del prisma, sino que rompen dos de las aristas angulares, otorgando así una mayor complejidad y dinamismo a la composición.

Cerramos el itinerario con un segundo ejemplo del museo cacereño, bajo el título Tensión cruzada. Lo consideramos uno de los más interesantes y se enmarca entre las propuestas del arte constructivo. Su autor, Feliciano Hernández (Gallegos de Altamiros, Ávila, 1936), ha realizado aportaciones esenciales a la escultura española en la combinación de elementos modulares, su interacción, la tensión dinámica y el equilibrio de pesos y fuerzas. Desde los años setenta explora este terreno con esculturas de hierro, acero, piedra o madera. Los componentes de sus obras desafían la fuerza de la gravedad contrarrestando sus presiones al encajarse unos en otros; pero también mediante tensores que sostienen las piezas en un equilibrio estable pero dinámico, resuelto por cálculos intuitivos y con una inteligente variedad en los soportes $^{36}$. Un parque escultórico monográfico erigido en Navalcarnero acoge algunas de las mejores creaciones del autor.

Tensión cruzada (2,5 x 1,5 x 1,5 m) utiliza el acero corten, pero sorprende la valentía del artista al presentarla con un intenso color naranja. Los elementos rectos y curvos que la componen se sustentan en apariencia por el sistema de cables y contrapesos, pero han sido soldados por razones de seguridad, al estar en un lugar público muy accesible. Esta escultura cacereña es una variante de la instalada en 1989 a escala monumental en la Urbanización Puerto Calero de Lanzarote. Al igual que aquélla duplica los efectos de tensión al proyectar los módulos en dos ejes direccionales; y a su vez los elementos curvos parecen configurar en el centro una esfera virtual, algo que enriquece aún más sus valores perceptivos.

Tras este recorrido, inevitablemente selectivo, podemos concluir que la incorporación de la abstracción a la escultura pública extremeña se ha desarrollado entre dos condicionantes principales.

Por una parte la necesidad de encontrar recursos plásticos que puedan adaptarse a unos fines conmemorativos sin contar con el poder narrativo de la imagen figurada. Los artistas utilizan para ello alusiones o símbolos que en muchos casos dificultan la comunicación con el espectador, quien puede aceptar la obra por razones puramente estéticas o resemantizar su contenido.

Por otro lado, se produce un salto cualitativo cuando a partir de los años ochenta y noventa del siglo XX se asume que la escultura puede asentarse en el espacio urbano sin necesidad de conmemorar un hecho o idea concreta. En estos casos, bien de forma aislada o formando parte de museos al aire libre, las obras se afirman por sus valores plásticos y pasa a un segundo plano su posible valor referencial. Ambas opciones han permitido, aunque en fechas tardias, que asistamos a una renovación de los modelos tradicionales y que la ciudadanía asuma con mayor naturalidad este tipo de propuestas. Si bien seguirá siendo una opción minoritaria y serán inevitables los recelos de ciertos sectores, entendemos que se tiende a un proceso de normalización, en el que lo deseable es que se cumplan altas exigencias de calidad.

36 AREÁN, Carlos, Feliciano, Madrid, Dirección General del Patrimonio, 1975; MARÍN MEDINA, José, Feliciano, Ávila, Caja de Ahorros de Ávila, 1986; GONZÁLEZ VICARIO, María Teresa, "Feliciano", en Espacio, Tiempo y Forma, Serie VII, Historia del Arte, vol. 3, Madrid, UNED, 1990, pp. 393-415; PÉREZ REYES, Carlos y BANGO GARCÍA, Illana, Feliciano. Tensiones, Madrid, AyuntamientoCentro Cultural Conde Duque, 2001; NIETO ALCAIDE, Víctor, Feliciano, Junta de Castilla y León, 2002. 
